\title{
Perfil dos egressos do curso de Odontologia da Universidade Federal do Ceará e suas percepções acerca do mercado de trabalho
}

\author{
João Pedro Coelho de Araujo*; Luiza Maria Dias Firmeza**; Maria Eneide Leitão de Almeida***; Ana \\ Karine Macedo Teixeira*** \\ * Graduado em Odontologia, Universidade Federal do Ceará \\ ** Mestre em Odontologia, Universidade Federal do Ceará \\ *** Professora Adjunta, área de Saúde Coletiva, Universidade \\ Federal do Ceará
}

Recebido: 20/04/2020. Aprovado: 25/01/2021.

\begin{abstract}
RESUMO
O objetivo do estudo foi identificar o perfil dos egressos de Odontologia da Universidade Federal do Ceará e suas percepções acerca do mercado de trabalho. Realizou-se um estudo transversal com aplicação de questionário online aos egressos de 2010/1 a 2018/1. Foram abordadas questões referentes ao perfil sociodemográfico, campo de atuação e percepção do mercado de trabalho e das suas limitações de formação. Realizou-se análise descritiva das variáveis e utilizou-se o teste t de Student e qui-quadrado, considerando um nível de significância de 5\%. Dos 435 egressos, 169 $(38,8 \%)$ participaram da pesquisa. A maioria $(83 \%)$ se inseriu no mercado de trabalho em até um mês de formado e possuía alguma titulação acadêmica de pós-graduação $(87,6 \%)$. A carga horária de trabalho de 44,3\% dos egressos é maior que 40 horas semanais, com remuneração média de 5,4 salários-mínimos, verificando-se uma desigualdade salarial e de carga horária de trabalho entre gêneros. Ainda, $15,7 \%$ atuavam na docência aliada a outra atividade, $15 \%$ no consultório particular e $25,3 \%$ possuíam vínculo com serviço público. A maioria dos egressos sentiram-se parcialmente preparados para o mercado de trabalho $(53,8 \%)$, sendo este avaliado majoritariamente como "regular" $(51,5 \%)$. Quanto ao nível de satisfação com a Odontologia, 76,8\% afirmaram ser bom ou excelente. Ademais, foram apontadas deficiências na formação nos conteúdos de gestão privada e pública. Conclui-se que os egressos apresentaram rápida inserção no mercado de trabalho, alta carga horária semanal de trabalho, boa satisfação com a profissão, apesar de considerarem o mercado de trabalho regular. Além disso, esse estudo sinaliza uma desigualdade de gênero no mercado de trabalho odontológico.
\end{abstract}

Descritores: Educação Odontológica. Desigualdade de Gênero. Mercado de Trabalho. 


\section{INTRODUÇÃO}

Ao longo dos anos, o número de graduados no ensino superior cresce no país, sendo observado que, de 2008 a 2018, o número de concluintes em cursos de graduação aumentou em $49 \%$ nas instituições privadas e 32,3\% nas públicas ${ }^{1}$. Apesar de a conquista da conclusão do ensino superior propiciar maior qualificação dos indivíduos, a sua expansão oportuniza uma maior dificuldade de ingresso no mercado de trabalho por ensejar uma desproporção na oferta e procura de emprego, além de uma crescente exigência por profissionais com amplo repertório de habilidades e competências ${ }^{2}$.

$\mathrm{Na}$ Odontologia, além do aumento do número de profissionais decorrente da maior oferta de novos cursos de graduação, outros diversos fatores têm propiciado, nas últimas décadas, alterações no perfil do mercado de trabalho odontológico, como as mudanças nas características epidemiológicas dos problemas de saúde bucal, a crescente demanda por assistência odontológica, o mercantilismo na saúde, a procura por serviços de caráter preventivo em vez de intervencionistas, as mudanças socioculturais da população e a reformulação do sistema público de saúde ${ }^{3,4}$.

Nesse cenário de modificação do padrão do mercado de trabalho na Odontologia, os pacientes contribuem de maneira ativa ao apresentarem uma maior exigência devido ao acesso facilitado à informação e às novas técnicas e tecnologias, demandando, cada vez mais, por cirurgiõesdentistas (CDs) que sejam especialistas, estejam presentes nas novas redes sociais e atualizados com as novas tecnologias do mercado. Esses fatores exigem um alto nível de excelência e conformam o mercado no qual o recém-graduado tentará se inserir ${ }^{4}$.

O ensino da Odontologia no Brasil é regulamentado pela Resolução CNE/CES 3, de 19 de fevereiro de 2002, que institui as Diretrizes Curriculares Nacionais (DCN) dos cursos de graduação em Odontologia. A partir das DCN, estabelece-se a formação de cirurgiões-dentistas generalistas, humanistas, críticos e reflexivos, para atuarem em todos os níveis de atenção à saúde, com base no rigor técnico e científico ${ }^{5}$. Nesse sentido, enfatiza-se a necessidade de avaliações periódicas das matrizes curriculares das instituições, para que se garanta que elas estejam de acordo com as DCN, acompanhando a progressão das tendências na Odontologia, incorporando adequadamente as tecnologias no cotidiano e contemplando as demandas dos setores nos quais os egressos irão trabalhar6.

As DCN dos cursos de graduação em Odontologia estabelecem que a formação do cirurgião-dentista deve capacitar o profissional para o exercício de habilidades e competências como atenção à saúde, tomada de decisão, comunicação, liderança, administração e gerenciamento e educação permanente, reconhecendo que a instituição de ensino deve prezar pela formação de profissionais críticos e reflexivos. Ademais, o documento define que os cursos de graduação em Odontologia devem contemplar os conteúdos de Ciências Biológicas e da Saúde, Ciências Humanas e Sociais e Ciências Odontológicas 5 .

Apesar de alguns estudos apontarem que cirurgiões-dentistas egressos sentem-se aptos para o mercado de trabalho, satisfeitos com o curso escolhido e com a proposta de ensino da graduação, ainda existem fragilidades e desafios a serem superados nas instituições de ensino superior, visando a um melhor processo formativo desses profissionais $^{7,8}$.

Estudos revelam que concluintes e egressos do curso de Odontologia apontam como dificuldades para a inserção no mercado de trabalho a insegurança, o despreparo para gerenciar serviços, assumir cargos e liderar equipes e a falta de experiência e aptidão, por vezes relacionada a deficiências do curso, do corpo docente e da prática 
de estágios ${ }^{9}$. Em adição a esses fatores, observa-se, sob a perspectiva dos egressos, desafios inerentes ao mercado de trabalho como baixo salário e saturação do mercado ${ }^{10}$.

Considerando esses desafios, é relevante identificar o perfil dos egressos e suas percepções acerca das dificuldades enfrentadas ao ingressar no mercado de trabalho, para melhorar a formação dos futuros cirurgiões-dentistas e nortear os projetos pedagógicos de curso, visto que as fragilidades das instituições e o desenvolvimento deficiente de habilidades e competências impactarão negativamente a formação discente ${ }^{11}$.

O curso de Odontologia da Universidade Federal do Ceará (UFC) foi fundado em 1916 e já comportou diferentes estruturas curriculares, sempre com o objetivo comum de melhorar a aprendizagem e a formação do egresso. Considerando que os egressos podem prover informações que norteiem novas reestruturações curriculares, realizou-se esse estudo que teve como objetivo identificar o perfil dos egressos da graduação em Odontologia na UFC e suas percepções acerca do mercado de trabalho.

\section{METODOLOGIA}

Foi realizado um estudo quantitativo e transversal, de janeiro a junho de 2019. A população do estudo correspondia aos cirurgiõesdentistas formados no curso de Odontologia da UFC no período de 2010/1 a 2018/1, totalizando 435 cirurgiões-dentistas, os quais foram identificados por meio de consulta aos registros de formandos que colaram grau em cada semestre, obtidos na coordenação do curso.

Foi aplicado um questionário online, o qual foi construído baseado nos estudos de Pinheiro e Noro $^{12}$ e Pinheiro et al. ${ }^{13}$, composto por dezesseis questões objetivas, divididas em quatro blocos: 1 . perfil sociodemográfico (idade, sexo, renda, tempo de inserção no mercado de trabalho, titulação acadêmica); 2. campo de atuação (local de trabalho, carga horária semanal, regime de trabalho); 3. percepção do mercado de trabalho (preparo para o mercado de trabalho, capacitação para o serviço e avaliação do mercado) e satisfação com a Odontologia; 4. áreas do conhecimento e habilidades/competências consideradas deficientes na sua formação.

O questionário foi enviado para o e-mail particular de cada egresso, obtido na secretaria da coordenação do curso. Houve três tentativas de contato via e-mail durante aproximadamente dois meses. Após esse período, utilizou-se a rede social Instagram e o WhatsApp como uma forma de contato com os egressos.

As habilidades/competências e áreas do conhecimento contempladas no questionário foram estabelecidas de acordo com as DCN do curso de Odontologia $^{5}$. Para identificar as áreas consideradas deficientes, questionou-se aos egressos acerca das áreas que foram pouco ou não exploradas na graduação.

Para aferir o "nível de satisfação com a Odontologia", utilizou-se uma escala de satisfação de 10 pontos. Para a análise dos dados, considerouse os seguintes parâmetros de satisfação: 0 a 2 (péssima), 3 e 4 (ruim), 5 e 6 (regular), 7 e 8 (bom) e 9 e 10 (excelente satisfação). A avaliação do mercado de trabalho foi aferida por meio de uma escala que foi construída baseando-se no estudo de Pinheiro et al. ${ }^{13}$, composta pelas alternativas: excelente (escore 1), bom (escore 2), regular (escore 3), ruim (escore 4) ou péssimo (escore 5).

Os dados foram analisados no programa SPSS versão 20.0 (IBM, Amronk, NY, EUA), onde realizou-se a análise estatística descritiva das variáveis e utilizou-se o teste qui-quadrado para verificar associação entre carga horária de trabalho semanal e gênero. Foi realizado o teste de normalidade de dados Kolmogorov-Smirnov. Visto que a variável renda apresentou distribuição normal, utilizou-se o teste paramétrico t de Student para verificar se havia diferença significativa entre 
as rendas médias mensais de acordo com o gênero. Para as análises estatísticas foi considerado um nível de significância de 5\%.

Ao serem contatados, os egressos tiveram acesso a um link contendo o termo de consentimento livre e esclarecido e somente após a leitura e concordância, os egressos tiveram acesso ao questionário na plataforma google formulários. A pesquisa foi aprovada no comitê de ética em pesquisa da UFC com número de parecer 3.119.154.

\section{RESULTADOS}

Dos 435 cirurgiões-dentistas que colaram grau entre o período de 2010/1 a 2018/1, 169 $(38,8 \%)$ participaram da pesquisa. Destes, $1,8 \%$ afirmaram não ter nenhum vínculo empregatício ligado à Odontologia. A tabela 1 apresenta o perfil sociodemográfico e a atuação no mercado de trabalho dos egressos de Odontologia da UFC. A maioria dos participantes eram do gênero feminino (65\%) e apresentaram rápida inserção no mercado de trabalho. Apenas 12,4\% afirmaram não possuir nenhuma titulação de pós-graduação, porém, $66 \%$ destes eram recém-formados. A maioria dos egressos possuíam como titulação máxima a especialização (32\%) e a área de titulação mais apontada foi a de Clínica Odontológica (28\%), seguida da Ortodontia (23\%), Cirurgia $(22,3 \%)$, Prótese (21\%) e Endodontia e Dentística (19,5\%)

Em relação à atuação no mercado de trabalho, a opção mais relatada foi a conciliação da docência com outro emprego $(15,7 \%)$, seguida pela atuação em consultório privado (15,1\%), Entre os que apresentavam vínculo com o serviço público (25,3\%), 13,3\% atuavam exclusivamente neste setor, sendo a maioria na Estratégia Saúde da Família (ESF). A maior parte dos participantes eram autônomos $(27,5 \%)$ e contratados ou comissionados $(22,8 \%)$ (tabela 1$)$.

No que diz respeito à carga-horária de trabalho, a opção mais apontada pelos egressos correspondeu à mais de 40 horas semanais $(44,3 \%)$ (tabela 1), sendo observado que a maioria dos homens $(57,6 \%)$ afirmaram possuir jornada de trabalho semanal maior que 40 horas, enquanto a maioria das mulheres $(42,6 \%)$ possuíam jornada de trabalho entre 30 e 40 horas semanais $(p=0,03)$ (tabela 2).

A renda média mensal dos egressos foi de $\mathrm{R} \$$ 5.422,41. Entretanto, essa renda apresentou uma diferença significativa $(p=0,001)$ quando avaliada por gênero: os homens relataram possuir uma renda mensal média de $\mathrm{R} \$ 6.910,41 \pm 4.615,83$ e as mulheres $\mathrm{R} \$ 4.615,83 \pm 2.436,18$. Ao comparar a renda por gênero segundo a carga horária de trabalho semanal, observou-se diferença na renda média entre os gêneros no grupo que trabalhava mais de 40 horas por semana ( $\mathrm{p}=0,001$ ), conforme a tabela 2 .

A percepção do egresso em relação ao mercado de trabalho e a satisfação com a Odontologia pode ser vista na tabela 3 , a qual indica que a maioria dos egressos afirmaram estar parcialmente preparados para atuar no mercado de trabalho $(53,8 \%)$, além de se sentirem mais capacitados para a atuação no serviço público $(53,3 \%)$. O mercado de trabalho foi avaliado majoritariamente como "regular" (51,5\%), e em relação à satisfação com a Odontologia, as alternativas mais indicadas pelos egressos foram: boa satisfação $(53,8 \%)$ e excelente satisfação $(23 \%)$.

As habilidades ou competências que os egressos mais sentiram dificuldade ou consideraram deficientes ao se formarem foram: administração de consultório odontológico (79,8\%), solicitação e interpretação de exames complementares $(26,6 \%)$ e prescrição medicamentosa $(23,6 \%)$ (tabela 4). Já em relação às áreas consideradas deficientes pelos egressos durante a sua formação, observou-se que gestão de serviço privado (88\%), gestão de serviço público (54,8\%), Disfunção Temporomandibular (DTM) 
$(54,8 \%)$ e Odontogeriatria $(51,8 \%)$ foram as mais citadas (tabela 4$).$

Tabela 1. Perfil sociodemográfico e atuação no mercado de trabalho dos egressos do curso de Odontologia da Universidade Federal do Ceará

\begin{tabular}{|c|c|c|}
\hline Variável & $\mathbf{n}$ & $\%$ \\
\hline \multicolumn{3}{|l|}{ Sexo } \\
\hline Feminino & 110 & 65,1 \\
\hline Masculino & 59 & 34,9 \\
\hline \multicolumn{3}{|l|}{ Tempo para conseguir $1^{\circ}$ emprego } \\
\hline Até 1 mês & 140 & 82,8 \\
\hline Entre 1 e 3 meses & 24 & 14,2 \\
\hline Entre 4 e 6 meses & 2 & 1,2 \\
\hline Mais de 6 meses & 3 & 1,8 \\
\hline \multicolumn{3}{|l|}{ Maior Titulação de Pós-Graduação } \\
\hline Nenhuma & 21 & 12,4 \\
\hline Aperfeiçoamento & 17 & 10,1 \\
\hline Especialização & 54 & 32,0 \\
\hline Residência & 8 & 4,7 \\
\hline Mestrado & 16 & 9,5 \\
\hline Doutorado & 5 & 3,0 \\
\hline Pós-Graduação Stricto Sensu + Lato Sensu & 43 & 25,4 \\
\hline \multicolumn{3}{|l|}{ Local de atuação } \\
\hline Consultório Particular Próprio/alugado & 25 & 15,1 \\
\hline Serviço Público exclusivo & 22 & 13,3 \\
\hline Docência & 6 & 3,6 \\
\hline Pós-Graduando & 17 & 10,2 \\
\hline Empresa de Plano Odontológico & 18 & 10,8 \\
\hline Serviço Público + Cons. Particular e/ou Plano & 20 & 12,0 \\
\hline Docência + outros & 26 & 15,7 \\
\hline Pós-Graduando + outros & 13 & 7,8 \\
\hline Outros & 19 & 11,4 \\
\hline \multicolumn{3}{|l|}{ Local de atuação no serviço Público } \\
\hline ESF & 33 & 68,8 \\
\hline CEO & 5 & 10,4 \\
\hline UPA & 2 & 4,2 \\
\hline HOSPITAL & 4 & 8,3 \\
\hline CEO+UPA ou ESF/ UPA+Militar & 4 & 8,3 \\
\hline \multicolumn{3}{|l|}{ Carga Horária Semanal Média } \\
\hline Até 30 horas & 29 & 17,4 \\
\hline Entre 30 e 40 horas & 64 & 38,3 \\
\hline Mais de 40 horas & 74 & 44,3 \\
\hline \multicolumn{3}{|l|}{ Vínculo Empregatício } \\
\hline Concurso Público & 18 & 10,8 \\
\hline Celetista & 37 & 22,2 \\
\hline Autônomo & 46 & 27,5 \\
\hline Contrato/Serviço Prestado/Comissionado & 38 & 22,8 \\
\hline Bolsista & 24 & 14,4 \\
\hline Celetista+Autônomo & 3 & 1,8 \\
\hline Prestação de Serviço sem Contrato & 1 & 0,6 \\
\hline
\end{tabular}

UPA: Unidade de Pronto Atendimento; CEO: *Centro de Especialidades Odontológicas; ESF: Estratégia Saúde da Família 
Tabela 2. Carga horária semanal de trabalho e renda média mensal (em Real) segundo o gênero dos egressos do curso de Odontologia da Universidade Federal do Ceará

\begin{tabular}{|c|c|c|c|c|c|c|}
\hline & \multicolumn{2}{|c|}{ Feminino } & \multicolumn{2}{|c|}{ Masculino } & \multirow[b]{2}{*}{ Média } & \multirow{2}{*}{$\begin{array}{l}\text { Valor } \\
\text { de } \mathbf{p}^{* *}\end{array}$} \\
\hline & n (\%) & $\begin{array}{l}\text { Renda } \\
\text { média }\end{array}$ & n (\%) & $\begin{array}{l}\text { Renda } \\
\text { média }\end{array}$ & & \\
\hline \multicolumn{7}{|c|}{ Carga horária semanal } \\
\hline Até 30 horas & $22(20,4)$ & $4.388,63$ & $7(11,9)$ & $5.277,14$ & $4.603,13$ & 0,80 \\
\hline $30-40$ horas $*$ & $46(42,6)$ & $4.418,67$ & $18(30,5)$ & $6.400,50$ & $4.976,06$ & 0,08 \\
\hline$>40$ horas* & $40(37,0)$ & $4.852,35$ & $34(57,6)$ & $7.313,64$ & $5.983,21$ & 0,001 \\
\hline
\end{tabular}

* Teste qui-quadrado $\mathrm{p}=0,03 \quad * *$ Teste $\mathrm{t}$ de Student

Tabela 3. Percepção do mercado de trabalho e satisfação com a Odontologia dos egressos do curso de Odontologia da Universidade Federal do Ceará

\begin{tabular}{lcc}
\hline Variável & $\mathbf{n}$ & $\mathbf{\%}$ \\
\hline Sentiu-se preparado para mercado de trabalho & & \\
Não & 47 & 27,8 \\
Parcialmente & 91 & 53,8 \\
Sim & 31 & 18,3 \\
\hline Sentiu-se mais capacitado para o serviço: & & \\
Ambos & 58 & 34,3 \\
Privado & 10 & 5,9 \\
Público & 90 & 53,3 \\
Não se sentiu capacitado & 11 & 6,5 \\
\hline Nível de satisfação com a Odontologia & & \\
Péssimo & 8 & 4,7 \\
Ruim & 4 & 2,3 \\
Regular & 27 & 15,9 \\
Bom & 91 & 53,8 \\
Excelente & 39 & 23,0 \\
\hline Avaliação do mercado de trabalho & & \\
Péssimo & 8 & 4,8 \\
Ruim & 34 & 20,4 \\
Regular & 86 & 51,5 \\
Bom & 36 & 21,6 \\
Excelente & 3 & 1,8 \\
\hline
\end{tabular}


Tabela 4. Habilidades/competências e áreas deficientes durante graduação segundo os egressos do curso de Odontologia da Universidade Federal do Ceará

\begin{tabular}{lcc}
\hline Variável & n & \% \\
\hline Habilidades/competências com deficiência & & \\
Administração de Consultórios & 135 & 79,8 \\
Solicitação/interpretação de exames complementares & 45 & 26,6 \\
Prescrição medicamentosa & 40 & 23,6 \\
Diagnóstico epidemiológico & 32 & 19,2 \\
Liderar equipe de saúde & 30 & 18,0 \\
Diagnosticar e propor plano de tratamento & 27 & 16,2 \\
Realizar trabalho multidisciplinar & 20 & 12,0 \\
Comunicação com paciente & 18 & 10,8 \\
Organização consultório & 9 & 5,4 \\
Dificuldade clínica/técnica & 6 & 3,6 \\
Ações de promoção em saúde & 2 & 1,2 \\
\hline Áreas com deficiência & & \\
Gestão de serviço privado & 146 & 88,0 \\
Gestão de serviço público & 91 & 54,8 \\
Disfunção Temporomandibular & 91 & 54,8 \\
Odontogeriatria & 86 & 51,8 \\
Pacientes Especiais & 46 & 28,0 \\
Saúde Coletiva & 23 & 14,0 \\
Ortodontia & 14 & 8,5 \\
Prótese & 11 & 6,6 \\
Implantodontia & 10 & 6,0 \\
Estética & 09 & 5,4 \\
Endodontia & 08 & 5,0 \\
Estomatologia & 06 & 3,6 \\
\hline
\end{tabular}

*Os participantes poderiam indicar mais de uma alternativa para habilidades/áreas deficientes durante graduação

\section{DISCUSSÃO}

A grande maioria dos egressos apresentaram rápida inserção no mercado de trabalho (em até um mês de formado) corroborando os achados de outros estudos ${ }^{6,12,13}$. Em relação ao local de atuação, o maior percentual $(15,7 \%)$ do estudo correspondeu à atuação na docência associada a outra atividade. Egressos de outros estudos revelaram predominantemente, em relação às suas atuações, uma conciliação do serviço privado com o serviço público ${ }^{8,14}$. Essas evidências parecem sinalizar uma mudança do paradigma da atuação exclusiva do cirurgião-dentista em consultório particular. Essa transição que tem sido observada pode estar associada à consciência das dificuldades do mercado, à incorporação da saúde bucal na ESF e à percepção dos benefícios inerentes ao serviço público como estabilidade financeira e vantagens trabalhistas ${ }^{6,10}$.

No atual estudo, a maioria dos dentistas que afirmaram trabalhar no serviço público atuavam na ESF, assim como no estudo de Pinheiro et al. ${ }^{13}$, realizado em 2011, que também investigou o perfil dos egressos da UFC. Ao comparar ambos os estudos se observou expressiva redução percentual do número de egressos atuando no serviço público, visto que no estudo de Pinheiro et al. ${ }^{13}$ esse percentual foi de $46,5 \%$ e no presente estudo foi de $25,3 \%$.

No período de 2010 a 2018, houve ligeiro aumento da cobertura populacional de saúde bucal na atenção básica no estado do Ceará, sugerindo que não houve fechamento de postos de trabalho ${ }^{15}$. Dessa forma, essa constatação do decréscimo do 
número de respondentes atuando no serviço público pode ser devido ao aumento do número de cirurgiões-dentistas formados a cada semestre no país e no estado do Ceará ${ }^{16}$. De acordo com o Conselho Federal de Odontologia (CFO), em apenas quatro anos, de 2015 a 2019, o número de instituições de ensino que ofertam a graduação em Odontologia cresceu $87 \%$, passando de 220 para 412. Assim, a ESF não consegue absorver todos os formandos ${ }^{17}$.

Decorrente desse cenário, sugere-se que a variabilidade de locais de atuação percebida no presente estudo representa os egressos do curso de Odontologia UFC encontrando outros campos de trabalho, além do serviço público. Nesse sentido, salienta-se que o aumento do número de cursos de graduação no estado pode ter viabilizado a inserção dos egressos na docência e na pós-graduação, oportunizando outro campo de atuação fora do serviço público.

A maioria dos egressos do estudo relatou ter jornada de trabalho maior do que 40 horas semanais, divergindo do resultado de Pinheiro et $a l .{ }^{13}$, que encontrou apenas $9,7 \%$ dos egressos trabalhando mais do que 40 horas, sendo que a maioria $(75,7 \%)$ afirmou trabalhar entre 31 e 40 horas, número expressivamente maior do que o encontrado no presente estudo. Sugere-se que esse aumento da carga horária seja devido ao mercado de trabalho odontológico brasileiro estar saturado nos grandes centros urbanos, tornando-o altamente competitivo. No Ceará, a relação de habitantes/CDs é de 619, enquanto no interior do estado este valor chega a 2992 habitantes/CD ${ }^{18}$.

A maioria dos egressos do presente estudo se sentiram preparados ou parcialmente preparados para o mercado de trabalho, semelhante ao estudo de Melo et al..$^{14}$, em que $76 \%$ dos egressos se consideraram aptos para exercer a profissão após a formatura. Foram apontados como motivos para tal aptidão estágios, monitorias, aperfeiçoamento durante a graduação e questões referentes ao curso e ao corpo docente ${ }^{14}$.

A maior parte dos egressos se sentiram capacitados para o serviço público $(53,3 \%)$, enquanto apenas $5,9 \%$ se sentiram capacitados para o serviço privado. Essa evidência parece estar alinhada com o achado de outro estudo ${ }^{8}$, o qual revelou alta confiança e segurança para a realização de ações e procedimentos da Atenção Primária em Saúde e dificuldades para a realização de procedimentos especializados como endodontia de dentes multirradiculares, exodontia de dentes inclusos e prótese fixa.

Comparativamente ao prévio estudo de Pinheiro et al. ${ }^{13}$ também realizado com egressos do curso de Odontologia da UFC, em 2011, observase uma pior avaliação do mercado de trabalho entre os egressos do atual estudo, visto que a maioria avaliou o mercado como "regular", enquanto que em 2011 o mercado foi, majoritariamente, considerado "bom”. Além disso, 4,8\% dos egressos do estudo avaliaram o mercado como péssimo, opção não relatada no estudo de Pinheiro et $a l .{ }^{13} \mathrm{e}$ o percentual de egressos que avaliaram o mercado como ótimo foi menor no presente estudo $(1,8 \%)$, quando comparado ao estudo de 2011 (4,9\%).

Apesar de o mercado de trabalho ter sido apontado como "regular" pela maioria dos egressos $(51,5 \%)$ e apenas $23,4 \%$ o terem avaliado como bom ou excelente, essa avaliação não influenciou a satisfação com a Odontologia, visto que $76,8 \%$ dos participantes relataram boa ou excelente satisfação com a área, assim como em outros estudos ${ }^{8,10,14}$. Este achado revela que, apesar das dificuldades do mercado de trabalho, os cirurgiões-dentistas apresentam-se satisfeitos com a profissão.

Sousa et $a l .{ }^{10}$ encontraram resultados semelhantes, pois apesar da percepção desfavorável do mercado, relacionada à sua saturação, condição financeira insuficiente da população e falta de preparo profissional, a maioria dos participantes relataram que cursariam novamente a Odontologia e apresentavam-se 
satisfeitos com a área. Observa-se que a admiração pela profissão, a vocação e a influência familiar são fatores que motivam a escolha pela Odontologia, sugerindo que outros aspectos, além da situação do mercado de trabalho, podem estar influenciando a satisfação com a profisssão ${ }^{8}$.

A grande maioria dos egressos possuíam alguma titulação acadêmica de pós-graduação, coincidindo com outros estudos ${ }^{9,12,14}$. Essa evidência pode refletir tanto uma alta exigência do mercado de trabalho, quanto uma formação de profissionais voltados para o modelo biomédico, o qual prioriza cirurgiões-dentistas especialistas em detrimento dos generalistas. Entretanto, esse achado também pode estar sinalizando uma insuficiência do aprendizado durante a formação, fazendo com que os egressos busquem cursos de pós-graduação a fim de suprir deficiências da graduação $0^{9,12,14}$.

No atual estudo, foi visto que a área de titulação acadêmica mais citada foi a de Clínica Odontológica, podendo ser explicado pelo fato de o mestrado e o doutorado da UFC serem em Clínica Odontológica. A segunda área mais citada foi a Ortodontia, reforçando o dado do CFO (2019) ${ }^{19}$, o qual indica que a área com maior número de especialistas no Brasil é a Ortodontia, com 26.897 profissionais registrados.

A renda média mensal dos egressos encontrada no estudo $(\mathrm{R} \$ 5.422,41)$ foi maior que a renda média mensal do município de Fortaleza $(2,8 \mathrm{SM})^{20}$ e do estado do Ceará $(\mathrm{R} \$ 2.095,00)^{21}$. Foi observado que a renda média mensal se apresentou menor entre as mulheres, bem como a carga horária de trabalho. Ao analisar a renda por carga horária, destaca-se que mesmo quando ambos os gêneros trabalhavam mais que 40 horas por semana, as mulheres apresentavam menor renda mensal, apontando uma desigualdade de gênero no mercado de trabalho odontológico. Tal diferença corrobora os dados do Instituto Brasileiro de Geografia e Estatísticas (IBGE) ${ }^{22}$ que apontou que mulheres ganham menos do que homens quando possuem a mesma formação e carga horária de trabalho.

Observa-se a feminização nos cursos de Odontologia ao longo do tempo ${ }^{6,7,16}$, mas essa mudança não parece ser acompanhada da igualdade entre os gêneros no mercado de trabalho. Destaca-se que a categoria gênero, atravessada por fatores históricos e sociais, estabelece parâmetros, os quais oportunizam uma distinção entre os seres humanos em femininos e masculinos. A partir do conceito de gênero entende-se que um conjunto de relações construídas culturalmente afirma desigualdades entre homens e mulheres, separando o lugar social das mulheres e dos homens. A partir dessa perspectiva, rompe-se com a visão do determinismo biológico para justificar a opressão feminina e as relações de poder desiguais ${ }^{23}$.

Nesse sentido, Thuler e Bandeira (2008) ${ }^{24}$ apontam que a escolha pela Odontologia entre as mulheres pode estar associada à perspectiva de maior autonomia em administrar seus horários, visando a um maior tempo para dedicação à tripla jornada de trabalho, visto que essa tarefa ainda é socialmente exercida predominantemente pelas mulheres. Assim, elas tendem a reduzir seu tempo de trabalho devido ao conflito entre vida familiar e profissional, o que pode justificar os resultados apontados no presente estudo em relação à carga horária de trabalho e gênero.

Uma análise mais aprofundada ainda é necessária para explicar a desigualdade de renda no grupo que trabalhava mais de 40 horas semanais, para verificar como ocorre a inserção no mercado de trabalho de diferentes especialidades odontológicas por gênero, somado ao local de atuação e tempo dedicado à qualificação profissional. Estudo observou que em algumas especialidades há maior predominância de algum gênero, assim como maior atuação do gênero feminino no serviço público ${ }^{16}$, o que pode implicar em diferente rentabilidade por gênero. 
A gestão de serviço privado e de serviço público foram as áreas mais indicadas como deficientes pelos egressos, indicando a necessidade de uma maior abordagem desses conteúdos no projeto pedagógico do curso, semelhante a outros cursos no país ${ }^{25,26}$. O estudo de Mania, Vargas e Ferreira $(2018)^{9}$ também revelou insegurança dos concluintes em Odontologia para gerenciar serviço público e privado e para assumir cargos em entidades e liderar equipes. Esses achados sinalizam uma possível limitação das instituições na abordagem dessas competências e sugerem a necessidade de se extrapolar esses aspectos e contemplar conteúdos como administração do local de trabalho e empreendedorismo.

A deficiência apontada pelos egressos referente às áreas de DTM e Odontogeriatria pode estar associada ao fato de que ambos os conteúdos são abordados dentro de outras disciplinas, inexistindo disciplinas específicas para tais temas. Entretanto, recentemente, a disciplina de Oclusão foi reformulada, aumentando a carga horária para os conteúdos relacionados à DTM, o que pode, a longo prazo, reverter o quadro encontrado.

No que diz respeito às habilidades $\mathrm{e}$ competências mais indicadas pelos egressos como deficientes destacam-se as dificuldades para solicitar e interpretar exames complementares e para realizar prescrição medicamentosa. Ressaltase que tais habilidades são contempladas nos conteúdos do projeto pedagógico do curso de Odontologia da UFC, e que diante da dificuldade revelada pelos egressos, sugere-se uma investigação da metodologia de ensinoaprendizagem desses conteúdos ao longo do curso, de forma que se possa extrapolar o desenvolvimento da competência cognitiva, para uma abordagem atitudinal que permita o estímulo à tomada de decisão, ao desenvolvimento da autonomia e à capacidade reflexiva.

Como limitações do estudo pontua-se o fato de que apenas 39\% dos egressos do período pesquisado participaram da pesquisa; tal perda do número de participantes pode estar relacionado com mudanças no e-mail de contato. Diante desse número, é necessária cautela para análise dos dados, para não ser feita inferência para a população de egressos desse período. $\mathrm{O}$ fato de a pesquisa ter sido autoaplicada por meio eletrônico pode ter configurado algum viés de resposta, entretanto, não desqualifica a pesquisa, visto que essa metodologia tem sido utilizada em pesquisas similares ${ }^{12,27}$. Espera-se que o presente estudo permita contribuir com um contínuo acompanhamento dos egressos de Odontologia da UFC, possibilitando ao curso uma rápida detecção de variações no mercado de trabalho, a fim de adaptar o currículo para melhor preparação de seus graduandos.

\section{CONCLUSÕES}

O estudo evidenciou uma rápida inserção no mercado de trabalho pelos cirurgiões-dentistas, elevada carga horária de trabalho, com variabilidade de local de atuação. A maioria dos egressos encontram-se satisfeitos com a profissão, apesar de não avaliarem o mercado de trabalho como favorável. $\mathrm{O}$ estudo também sinalizou uma desigualdade de gênero no mercado de trabalho odontológico e revelou, ainda, a necessidade de uma melhor abordagem dos conteúdos de gestão privada e pública durante a graduação.

\section{ABSTRACT \\ Alumni profiling of dentists who graduated from the Federal University of Ceará and their perceptions on the labor market}

This study aimed to identify the alumni profile of dentists who graduated from the Federal University of Ceara and to explore their perceptions of the labor market. A cross-sectional study was carried out with the application of a questionnaire to graduates from 2010/1 to 2018/1, via google forms. The data were analyzed through descriptive statistics and by the Student's and Chi-squared tests 
with the significance level set at 5\%. One hundred and sixty-nine $(38.8 \%)$ out of 435 alumni dentists participated in the research. The majority of them (83\%) started working up to one month after graduation and had also completed a graduate course $(87.6 \%)$ by the time of the data collection. The working hours of $44.3 \%$ of the participants exceed 40 hours per week. The mean salary of the participants is 5.4 minimum wages, and an imbalance between worked hours and salary was found when comparing different genders. Additionally, while $15.7 \%$ of the participants worked as professors, associating this occupation with other professional activities, $15 \%$ of the alumni dentists worked in private dental offices and $25.3 \%$ worked in the public service. After graduating, most of the dentists felt partially prepared for the job market (53.8\%), which was evaluated as "regular" (51.5\%). Regarding the level of satisfaction with the field of dentistry, $76.8 \%$ of the participants perceived the dental profession as good and excellent. However, the alumni dentists pointed deficiencies regarding their education on the topics of private and public management. Therefore, it can be concluded that the alumni dentists were promptly absorbed by the job market, have a high weekly workload, are satisfied with the profession, but consider the job market only as regular. Moreover, this investigation brings light to gender inequalities in the labor market of dentistry.

Descriptors: Education, Dental. Gender Inequalities. Labor Market.

\section{REFERÊNCIAS}

1. Brasil. Instituto Nacional de Estudos e Pesquisas Educacionais Anísio Teixeira (Inep). Censo da Educação Superior 2018: notas estatísticas. Brasília, 2019.

2. Teixeira MAP, Gomes WB. Estou me formando... e agora? Reflexões e perspectivas de jovens formandos universitários. Rev ABOP. 2014;5(1):47-62.

3. Narvai PC, Frazão P, Roncalli AG, Antunes JLF. Cárie dentária no Brasil: declínio, polarização, iniquidade e exclusão social.
Rev Panam Salud Publica. 2006;19:385-93.

4. Bleicher L. O Dentista e o Mercado de Trabalho. In: Chaves SCL (Org). Política de Saúde Bucal no Brasil. Salvador: EDUFBA; 2016. p. 255-72.

5. Brasil. Ministério da Educação. Conselho Nacional de Educação. Resolução CNE/CES 3, de 19 de fevereiro de 2002. Institui Diretrizes Curriculares Nacionais do Curso de Graduação em Odontologia [Internet]. [Acesso em: 10 fev. 2019]. Disponível em: http://portal.mec.gov.br/ cne/arquivos/pdf/CES032002.pdf.

6. Ferraz MÂAL, Nolêto MDSC, Martins LLN, Bandeira SRL, Portela SGC, Pinto PHV et al. Perfil dos egressos do curso de Odontologia da Universidade Estadual do Piauí. Rev ABENO. 2018;18(1):56-62.

7. Silva ACRM, Garrido TM, Hayacibara MF, Bispo CGC, Silva RL, Morita MC et al. Perfil de cirurgiões-dentistas formados por um currículo integrado em uma instituição de ensino pública brasileira. Rev ABENO. 2012;12(2):147-54.

8. 8.Querino JPFO, Peixoto LR, Sampaio GAM. Perfil dos concluintes de Odontologia da Universidade Estadual da Paraíba, Rev ABENO. 2018;18(1):170-81.

9. Mania TV, Vargas AMD, Ferreira EF. Inserção no mundo do trabalho odontológico: percepção de graduandos em Odontologia sobre habilidades adquiridas e expectativas. Rev ABENO. 2018; 18(3):148-58.

10. Sousa JED, Maciel LKB, Oliveira CASD, Zocratto KBF. Mercado de trabalho em Odontologia: perspectivas dos estudantes concluintes de faculdades privadas no município de Belo Horizonte, Brasil. Rev ABENO. 2017;17(1):74-86.

11. Dias AMI, Zanin ICJ. Projeto político pedagógico do curso de Odontologia. Dias 
AMI, Zanin ICJ; Comissão de Docentes do Curso de Odontologia da UFC. Projeto Pedagógico de Curso: Graduação em Farmácia, Odontologia e Enfermagem. Fortaleza: Imprensa Universitária da Universidade Federal do Ceará; 2006. p. 28-45.

12. Pinheiro IAG, Noro LRA. Egressos de Odontologia: o sonho da profissão liberal confrontado com a realidade da saúde bucal. Rev ABENO. 2016;16(1):13-24.

13. Pinheiro VC, Menezes LMBD, Aguiar ASWD, Moura WVBD, Almeida MELD, Pinheiro FMDC. Inserção dos egressos do curso de Odontologia no mercado de trabalho. RGO. 2011;59(2):277-83.

14. Melo Júnior PC, Gurgle LGF, Guimarães RP, Souza LC, Pedrosa MS, Vicente da Silva CH. Perfil dos egressos do Curso de Odontologia da Universidade Federal de Pernambuco. Rev ABENO. 2018; 18(3):93-104.

15. Ministério da Saúde (BR). Relatório da Cobertura de Saúde Bucal, 2010 a 2018. Brasília: Ministério da Saúde; 2018.

16. Morita MC, Haddad AE, Araújo ME. Perfil atual e tendências do cirurgião-dentista brasileiro. Maringá: Dental Press International, 2010. v.1 96p.

17. Conselho Federal de Odontologia. CFO reforça necessidade do Ministério da Educação suspender autorizações para abertura de novos cursos de odontologia [Internet]. [Acesso em: 10 fev. 2019]. Disponível em: https://website.cfo.org.br/ cfo-reforca-necessidade-do-ministerio-daeducacao-suspender-autorizacoes-paraabertura-de-novos-cursos-de-odontologia/.

18. San Martin AS, Chisini LA, Martelli S, Sartori LRM, Ramos EC, Demarco FF. Distribuição dos cursos de Odontologia e de cirurgiões-dentistas no Brasil: uma visão do mercado de trabalho. Rev ABENO. 2018;18(1):63-73.
19. Conselho Federal de Odontologia. Quantidade Geral de Cirurgiões-Dentistas Especialistas [Internet]. [Acesso em: 2 mar. 2020]. Disponível em: https://website. cfo.org.br/estatisticas/quantidade-geral-decirurgioes-dentistas-especialistas/.

20. IBGE. Salário médio mensal dos trabalhadores formais do município de Fortaleza, 2018.

21. IBGE. Rendimento real habitual do trabalho principal no Estado do Ceará, 2019.

22. IBGE. Estatísticas de Gênero Indicadores sociais das mulheres no Brasil. Informação Demográfica e Socioeconômica n. 38. Rio de Janeiro: IBGE; 2018. 162 p.

23. Muylaert CJ, Delfini PSS, Advincula AO. Relações de gênero entre familiares cuidadores de crianças e adolescentes de serviços de saúde mental. Physis. 2015;25(1):41-58.

24. Thuler LA, Bandeira L. Sobre astrônomas alemãs e odontólogas no Brasil Central. Fazendo Gênero 8 - Corpo, Violência e Poder. Florianópolis, 2008.

25. Rocha NB, Higarashi IH. Ensino de gestão em saúde nos cursos paranaenses de Odontologia. Rev ABENO. 2019;19(3):78-86.

26. Saliba Garbin CA, Saliba TA, Ísper Garbin AJ, Custódio LBM, Moimaz SAS. Undergraduate education in Brazil: the students' curricular perspective of Dental care training. Rev ABENO. 2018;18(4):95-102.

27. Costa BAO, Gonçalves CF, Zanin L, Flório FM. Inserção de egressos de Odontologia do Tocantins no mercado de trabalho. Rev ABENO. 2016;16 (2): 93-104.

\section{Correspondência para: \\ Luiza Maria Dias Firmeza \\ e-mail: luizafirmeza@gmail.com \\ Avenida Abolição, 3090 \\ 60165-078 Fortaleza/CE}

